\title{
Severe cytokine release syndrome resulting in purpura fulminans despite successful response to nivolumab therapy in a patient with pleomorphic carcinoma of the lung: a case report
}

\author{
Osamu Honjo ${ }^{1}$, Terufumi Kubo ${ }^{2 *}$, Fumiko Sugaya ${ }^{4}$, Takahiro Nishizaka ${ }^{3}$, Koji Kato ${ }^{2,5}$, Yoshihiko Hirohashi², \\ Hiroki Takahashi ${ }^{5}$ and Toshihiko Torigoe ${ }^{2}$
}

\begin{abstract}
Background: Immune checkpoint inhibitors (ICIs) have provided more options in the treatment of lung cancer. However, ICls can cause several unfavorable reactions generally referred to as immune-related adverse effects.

Case presentation: In this report, we present the case of a 52-year-old woman with successful regression of pleomorphic carcinoma of the lung following nivolumab therapy. She developed purpura fulminans (PF) ultimately resulting in amputation of both lower extremities. Blood tests revealed thrombocytopenia with increased serum soluble IL-2 receptor, ferritin, and triglyceride levels suggesting hemophagocytic lymphohistiocytosis (HLH). In addition, serum A disintegrin-like and metalloproteinase with thrombospondin type 1 motifs 13 activity was decreased, suggesting thrombotic thrombocytopenic purpura (TTP). Further detailed analysis revealed severe hypercytokinemia including increased levels of IL-1 $\beta$, IL-6, IL-10, TNFa, IFNY, and G-CSF.

Conclusion: The severe systemic inflammatory reaction and impaired peripheral circulation in this patient was attributed to excessive immunological effect induced by nivolumab resulting in cytokine release syndrome (CRS). This is the first report of a patient with multiple pathological conditions including HLH, TTP-like condition, and PF presumably arising from ICl-induced CRS. Further accumulating thoroughly investigated cases would lead to better understanding of the disease and development of reliable cancer immunotherapy.
\end{abstract}

\section{Background}

Immune checkpoint inhibitors (ICIs) are promising alternatives in cancer treatment in addition to surgery, chemotherapy, and radiotherapy. The basic mechanism of action of ICIs is releasing the brakes of the immune regulation, which is a crucial negative feedback mechanism for avoiding excessive immune reaction. Therefore, ICI therapy has resulted in outstanding success on the one hand and lethal immune-related adverse effects (irAEs) on the other, which are now becoming a major concern in further development of reliable cancer

\footnotetext{
* Correspondence: kuboteru@sapmed.ac.jp

${ }^{2}$ Department of Pathology, Sapporo Medical University, School of Medicine,

South 1, West 17, Chuo-ku, Sapporo, Hokkaido 060-8556, Japan

Full list of author information is available at the end of the article
}

immunotherapy [1]. Hematologic adverse effects in particular are life-threatening but occur relatively infrequently; 7 cases of hemophagocytic lymphohistiocytosis (HLH) following ICI therapy have been reported so far (4 cases of melanoma and 1 case each of urinary bladder carcinoma, Merkel cell carcinoma, and non-small cell lung carcinoma) [2-6]. There has been only 1 reported case of thrombotic thrombocytopenic purpura (TTP) following ICI therapy with ipilimumab [7].

In this report, we present a case of pleomorphic lung carcinoma with significant anti-tumor response to nivolumab therapy. The patient also developed severe cytokine release syndrome (CRS), resulting in HLH and amputation of both lower extremities because of purpura fulminans

(c) The Author(s). 2019 Open Access This article is distributed under the terms of the Creative Commons Attribution 4.0 International License (http://creativecommons.org/licenses/by/4.0/), which permits unrestricted use, distribution, and reproduction in any medium, provided you give appropriate credit to the original author(s) and the source, provide a link to the Creative Commons license, and indicate if changes were made. The Creative Commons Public Domain Dedication waiver (http://creativecommons.org/publicdomain/zero/1.0/) applies to the data made available in this article, unless otherwise stated. 
(PF) probably induced by a TTP-like condition. This is the first report of such a case.

\section{Case presentation}

A 52-year-old woman visited a hospital with complaints of right axillary swelling. Computed tomography (CT) imaging identified a space-occupying lesion in the S2 region of the right lung. On histological analysis, the tumor showed high-grade cytological atypia with poor intercellular cohesion (Fig. 1a). Immunohistochemical analysis revealed that the tumor was positive for pan-cytokeratin, vimentin, and thyroid transcription factor 1, but negative for CD45 and CD30, indicating pleomorphic adenocarcinoma of the lung. Programmed cell death ligand 1 was positive in more than $95 \%$ of tumor cells (Anti-PD-L1, Clone 22C3; DAKO, Glostrup, Denmark; data not shown). The tumor was evaluated as cT4N2M0 in accordance with TNM classification of Malignant Tumors 8th edition (Union for International Cancer Control, Geneva, Switzerland). The patient underwent four courses of chemotherapy (nab-paclitaxel plus carboplatin). She had fever, polyarthralgia, and muscle soreness. In addition, leukocytosis and thrombocytosis were detected on laboratory testing (data not

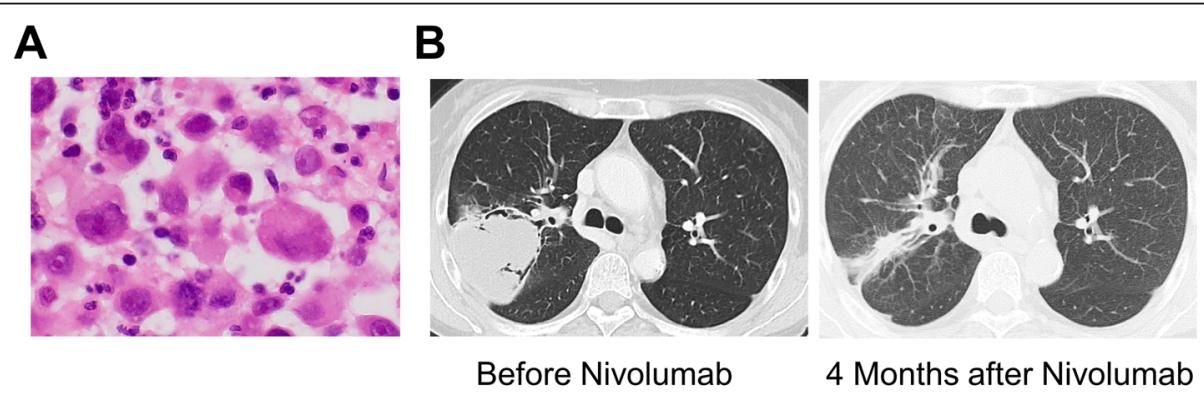

C

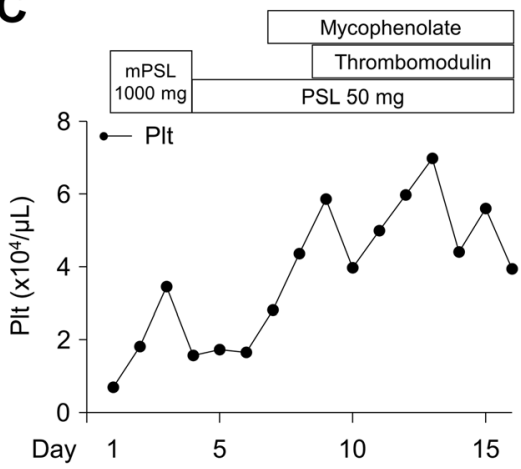

D

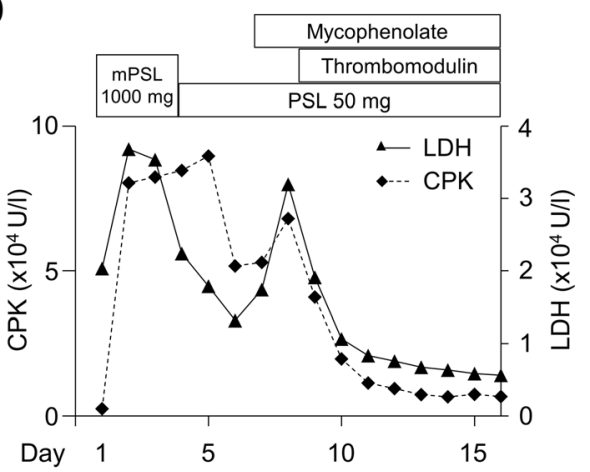

E

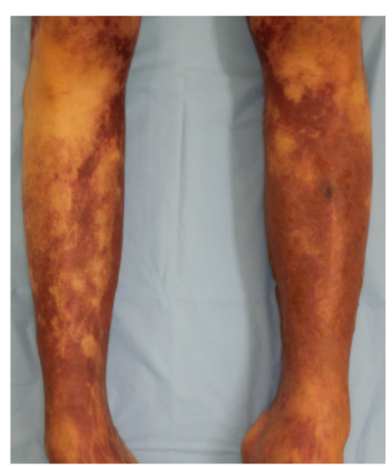

Day 2

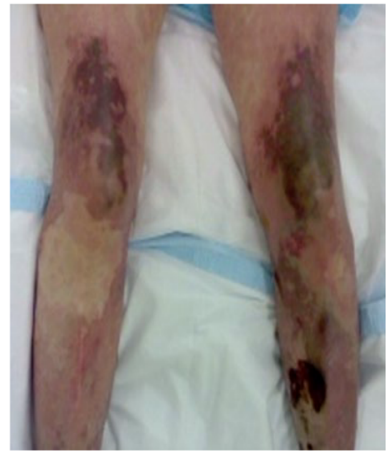

Day 10

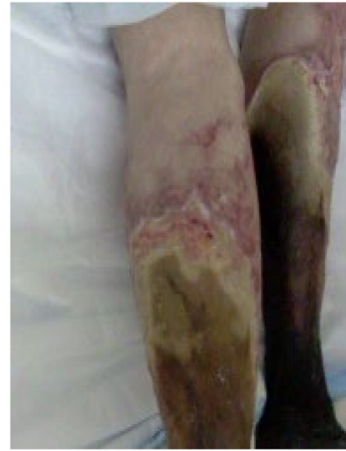

After 2 Month

Fig. 1 Clinical data and pathological images. a Tumor cells with a pleomorphic appearance but are less cohesive. Hematoxylin and eosin staining; original magnification $\times 200$. b Computed tomography imaging shows a low-intensity lesion measuring approximately $7 \mathrm{~cm}$ in $\mathrm{S} 2 \mathrm{of}$ the right lung (left panel). By 4 months after the last nivolumab administration, no distinctive space-occupying lesion is found (right panel). Graphs representing the trends of $\mathbf{c}$ platelet count, $\mathbf{d}$ LDH and CPK from the time of admission (day 1 ) to day 16. e Images of the lower extremities at 2 days (left panel), 10 days (center panel), and 2 months (right panel) after the onset of purpura fulminans 
shown). Based on these clinical features, she was diagnosed as having paraneoplastic syndrome and not an adverse effect of chemotherapy because of paucity of association between symptoms and medication. The patient showed a partial response to chemotherapy based on the Response Evaluation Criteria in Solid Tumors guidelines at which time the tumor was $70 \times 55 \times 48 \mathrm{~mm}$ in size (Fig. 1b; left panel). Then, she was treated with four courses of $120 \mathrm{mg}(3 \mathrm{mg} / \mathrm{kg})$ of nivolumab every 2 weeks. Although the patient still had the same symptoms that was diagnosed as paraneoplastic syndrome before, there was no newly developed prodrome or mild noticeable irAEs until the last administration of nivolumab. In addition, laboratory tests performed in each hospital visit did not show any remarkable abnormality.

However, 14 days after the last nivolumab administration, she was admitted to our hospital with complaints of asthenia. The patient felt sick only one day before the admission. She had a fever of $38.6{ }^{\circ} \mathrm{C}$. There was livedo reticularis on the extremities with systemic purpura. Laboratory results on admission are shown in Table 1. The patient had no relevant past medical history or family history including autoimmune disease. In addition, autoantibodies, including antinuclear antibodies, proteinase 3, myeloperoxidase-antineutrophil cytoplasmic, and anticardiolipin antibodies, as well as multiple aminoacyltRNA synthetases or anti-CL- $\beta 2$ GP1 antibodies, were not detected. Culture and microscopy of the blood smear did not detect bacterial infection. Conversely, significantly increased serum levels of IL-1 $\beta$, IL-6, IL-10, TNF $\alpha$, IFN $\gamma$, and G-CSF indicated a state of cytokine storm. Thrombocytopenia and increased serum soluble IL-2 receptor, ferritin, and triglyceride levels would imply possible HLH. Impaired liver function with increased lactate dehydrogenase and creatine phosphokinase together with exacerbated muscle soreness suggested rhabdomyolysis. The activity of A disintegrin-like and metalloproteinase with thrombospondin type 1 motifs 13 (ADAMTS13) was decreased but not less than $10 \%$, which is a criterion for TTP. There was no evidence of infection on blood culture.

Immediately after admission to the intensive care unit, pulse steroid therapy with methylprednisolone $1000 \mathrm{mg} /$ day for 3 days and systemic prednisolone administration $(50 \mathrm{mg} /$ day) were instituted. Thrombomodulin and mycophenolate mofetil was administered thereafter. Any of them could not provide a dramatic amelioration of her general condition, although the laboratory test showed improvement after administration of thrombomodulin and mycophenolate. Trend of platelet count, blood concentration of lactate dehydrogenase and creatine phosphokinase, which were useful as indicator of the clinical state, are depicted in Fig. 1c and d. By 3 days after hospitalization, general hypokinesis of the left ventricular wall resulted in reduced ejection fraction (20\%) and aggravation of respiratory distress. Although we did not perform myocardial biopsy, this was probably caused by CRS induced myocarditis, as evidenced by increased levels of the cardiac marker creatine kinasemuscle/brain in the circulation. Continuous hemodiafiltration was also initiated because of renal failure.

By 7 days after hospitalization, the lower extremities were turning black due to circulatory failure (Fig. 1e). Gangrene then spread with infection involving the entire lower extremities, suggesting PF. Amputation of the left and right lower limbs was performed at three and four months after admission, respectively. We could not find active microangiopathy or inflammation in the resected limbs presumably because of the modification by immune suppressants and complete necrosis.

CT evaluation of the pulmonary lesion at 4 months after the last administration of nivolumab demonstrated significant regression; the tumor had become a scar-like lesion (Fig. 1b; right panel) and there was no further progression thereafter. The patient was finally discharged from the hospital at 6 months after admission.

\section{Discussion}

In this case, the patient had pleiomorphic carcinoma treated with programmed cell death-1 (PD-1) inhibitor (nivolumab) and developed severe CRS. Inhibition of PD-1 mediated immunoregulation dramatically enhances anti-tumor immunity in many cancer patients. On the other hand, 30 to $40 \%$ of patients who had received nivolumab for non-small cell carcinoma of the lung developed complication of irAEs [8,9], which often require systemic corticosteroid therapy. It is worth mentioning that patients with irAEs tend to show better progression-free survival in non-small cell lung cancer [10]. This phenomenon suggests that the clinical effects and harmful side-effects of cancer immunotherapy are two sides of the same coin, making cancer immunotherapy that much more difficult. Furthermore, there is no reliable biomarker for estimating clinical efficacy or impending side-effect, although multifarious investigations have been carried out to identify candidate biomarkers from the clinical, pathological, and genetic point of view $[8,9]$. For example, paraneoplastic syndrome, a relatively rare condition, is considered to be induced by auto-immune reaction to tumor cells [11]. It would follow, therefore, that this syndrome would be a sign of the immunological effect of ICIs; however, there have been no reports showing any correlation between paraneoplastic syndrome and the efficacy of ICIs. Another candidate predictive marker is morphological atypia, which should be associated with tumor mutation burden, being a recently approved indicator of effect of ICIs. Since pleomorphic carcinoma shows significantly 
Table 1 Laboratory test results on admission

\begin{tabular}{|c|c|c|c|}
\hline Test & & Result & $\begin{array}{l}\text { Reference Renge } \\
\text { (Unit) }\end{array}$ \\
\hline \multirow{12}{*}{$\begin{array}{l}\text { Complete blood } \\
\text { count }\end{array}$} & Neutrophils & 2630 & 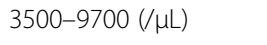 \\
\hline & Lymphocytes & 12.0 & $18.0-50.0(\%)$ \\
\hline & Monocytes & 0.0 & $1.0-8.0(\%)$ \\
\hline & Eosinophils & 0.0 & $0.0-7.0(\%)$ \\
\hline & Basophils & 0.0 & $0.0-2.0(\%)$ \\
\hline & RBCs & 492 & $376-516 \times 10 \wedge 4(/ \mu \mathrm{L})$ \\
\hline & Hemoglobin & 12.8 & $11.2-15.2(\mathrm{~g} / \mathrm{dL})$ \\
\hline & Hematocrit & 39.0 & $34.3-45.2(\%)$ \\
\hline & RBCs MCV & 79 & 80-101 (fL) \\
\hline & $\mathrm{RBCs} \mathrm{MCH}$ & 26.0 & $26.4-34.3(p g)$ \\
\hline & RBCs MCHC & 32.6 & 31.3-36.1 (\%) \\
\hline & Platelets & 1.1 & $14.0-37.9 \times 10 \wedge 4(/ \mu \mathrm{L})$ \\
\hline \multirow[t]{8}{*}{ Coagulation } & PT & 23.3 & $10.0-13.0$ (sec) \\
\hline & INR & 1.94 & $0.90-1.13$ \\
\hline & Fibrinogen & 185 & $170-410(\mathrm{mg} / \mathrm{dL})$ \\
\hline & D-dimer & $>60$ & $<1(\mu \mathrm{g} / \mathrm{mL})$ \\
\hline & TAT & $>120$ & $<4.0(\mathrm{ng} / \mathrm{mL})$ \\
\hline & $\begin{array}{l}\text { Lupus } \\
\text { anticoagulant }\end{array}$ & 1.3 & $<1.3$ (normalized ratio) \\
\hline & vWF activity & $>200$ & 50-150 (\%) \\
\hline & Thrombomodulin & $>32$ & 1.8-3.9 (FU/ml) \\
\hline \multirow[t]{18}{*}{ Blood Chemistry } & Urea & 8.9 & 2.7-7.0 (mg/dL) \\
\hline & Creatinine & 1.81 & $0.46-0.82(\mathrm{mg} / \mathrm{dL})$ \\
\hline & Sodium & 137 & $135-145(\mathrm{mEq} / \mathrm{L})$ \\
\hline & Potassium & 4.2 & 3.5-5.0 (mEq/L) \\
\hline & Chloride & 101 & 98-108 (mEq/L) \\
\hline & Total protein & 5.6 & $6.5-8.2(\mathrm{~g} / \mathrm{dL})$ \\
\hline & Albumin & 2.8 & $3.7-5.5(\mathrm{~g} / \mathrm{dL})$ \\
\hline & Triglyceride & 357 & 50-149 (mg/dL) \\
\hline & $\begin{array}{l}\text { Alkaline } \\
\text { phosphatase }\end{array}$ & 878 & 104-338 (U/L) \\
\hline & Total bilirubin & 4.0 & $0.3-1.2(\mathrm{mg} / \mathrm{dL})$ \\
\hline & Direct bilirubin & 3 & $<0.4(\mathrm{mg} / \mathrm{dL})$ \\
\hline & AST & 1556 & 10-40 (U/L) \\
\hline & ALT & 543 & 5-45 (U/L) \\
\hline & LDH & 3679 & 120-245 (U/L) \\
\hline & CK & 8040 & 5-210 (U/L) \\
\hline & CK-MB & 184.2 & $<5.0(\mathrm{ng} / \mathrm{mL})$ \\
\hline & Ferritin & 3877 & 21.8-274.7 (ng/mL) \\
\hline & CRP & 41.79 & $<0.30(\mathrm{mg} / \mathrm{dL})$ \\
\hline \multirow{4}{*}{$\begin{array}{l}\text { Cytokine or bioactive } \\
\text { substance }\end{array}$} & $\mathbb{I L}-1 \beta$ & 34.9 & $<0.928(\mathrm{pg} / \mathrm{mL})$ \\
\hline & $\| \mathrm{L}-2$ & $<15.6$ & $<15.6(\mathrm{pg} / \mathrm{mL})$ \\
\hline & soluble IL-2R & 3630 & 145-519 (U/mL) \\
\hline & IL-6 & 1510 & $<2.41(\mathrm{pg} / \mathrm{mL})$ \\
\hline
\end{tabular}

Table 1 Laboratory test results on admission (Continued)

\begin{tabular}{llll}
\hline Test & $\begin{array}{l}\text { Result } \\
\text { Reference Renge } \\
\text { (Unit) }\end{array}$ \\
\hline IL-10 & 20.0 & $<2.03(\mathrm{pg} / \mathrm{mL})$ \\
$\mathrm{IL}-12$ & $<0.78<3.15(\mathrm{pg} / \mathrm{mL})$ \\
TNFa & $251<1.79(\mathrm{pg} / \mathrm{mL})$ \\
INFY & $9260<20.6(\mathrm{pg} / \mathrm{mL})$ \\
G-CSF & $753 \quad 10.5-57.5(\mathrm{pg} / \mathrm{mL})$ \\
ADAMTS-13 & 37.8 & $70.0-120.0(\%)$ \\
activity & & \\
ADAMTS-13 & $<0.5<0.5(\mathrm{BU} / \mathrm{mL})$ \\
inhibitor & &
\end{tabular}

Abbreviations: $M C V$ mean corpuscular volume, $M C H$ mean corpuscular
hemoglobin, $M C H C$ mean corpuscular hemoglobin concentration, $P T$
prothrombin time, INR international normalized ratio, $T A T$ turnaround time,
AST aspartate aminotransferase, $A L T$ alanine aminotransferase, $L D H$ lactate
dehydrogenase, $C K$ creatine kinase, $C K-M B$ creatine kinase-muscle/brain, $C R P$
C-reactive protein

high-grade atypia as found in this case, it might be possible to predict both the beneficial and harmful effects of nivolumab. The problem is that quantifying morphological atypia with high reproducibility is challenging in practice. Currently, routine measurement of serum inflammatory cytokines is not common in daily clinical practice. However, monitoring some types of serum cytokines for a certain period would be helpful in predicting the beneficial or detrimental effects of cancer immunotherapy.

We observed increased serum levels of IL-1 $\beta$, IL-6, TNF $\alpha$, IFN $\gamma$, and G-CSF, which are known to be pleiotropic inflammatory cytokines that produce a myriad of systemic symptoms. In particular, increased IL-6 is a supposed culprit of myocardial disease and coagulopathy, which was observed in this case, although detailed mechanism is still obscure [12]. Clinically identified fever, thrombocytopenia and increased triglyceride, ferritin, and soluble IL-2 receptor levels suggested the presence of HLH, although the widely used Histiocyte Society HLH-2004 diagnostic criteria were not fully met. However, according to the recently proposed HScore evaluation, a novel sophisticated criterion, the score of this patient was 205 corresponding to more than $90 \%$ probability of HLH [13]. IL-6 is thought to be involved in the pathogenesis of HLH [14]. In contrast, an interesting report suggested that highly activated CD8 positive $\mathrm{T}$ lymphocytes induced regulatory $\mathrm{T}$ cell (Treg) dysfunction in patients with HLH [15]. The mechanism is explained by overconsumption of IL- 2 by CD8 positive T cells, resulting in decreased Treg number. Indeed, the number of Tregs is significantly decreased in patients with HLH and recovers to normal levels along with clinical improvement. In line with the focus of this report, the basic mechanism of action of ICIs themselves, activation of CD8 positive cells and suppression of 
Tregs, can be the fundamental cause of HLH. We suspected the same for secondary TTP as well. We found decreased ADAMTS13 activity, but ADAMTS13 inhibition was not detected. We therefore speculate that the release of multiple inflammatory cytokines hindered the generation of ADAMTS13 from stellate cells, endothelial cells, and platelets, leading to secondary TTP-like microcirculatory impairment resulting in PF, although we cannot exclude a possible subclinical heterogenous ADAMTS13 mutation. This hypothesis is supported by an experimental model where inflammatory cytokines, including TNF $\alpha$ and IFN $\gamma$, inhibited synthesis of ADAMTS13 from hepatic stellate cells, a major source of ADAMTS13 [16].

Overall, we propose that all the deleterious hematopoietic adverse effects seen in this case can be attributed to CRS induced by nivolumab-mediated overactivated immune reaction. At the moment, four types of possible mechanisms underlying irAEs have been proposed; overactivation of cellular immune, increasing humoral immune, excessive inflammatory cytokine production and enhancing complement-mediated inflammation [17]. Our current case would be included in "excessive inflammatory cytokine production" pattern. However, we could not identify exact causative factor or specific signaling pathway of this case.

\section{Conclusion}

We encountered a case of multiple pathologies including HLH, TTP-like condition, and PF presumably arising from ICI-induced CRS. To our knowledge, ours is the first report to describe this. CRS has been reported in the setting of autoimmune disease and bacterial or viral infection. However, expanding indications and advancing effectiveness of ICIs would increase the incidence of this disease in cancer patients. Although our current case showed significantly high blood concentration of IL-1 $\beta$, IL-6, TNF $\alpha$, and IFN $\gamma$ when compared with previous reports of CRS [18-20], we did not use the inhibitory agents for inflammatory cytokines in this case because these were not yet recommended in the actual clinical setting at that time. However, a study reported that administration of anti-IL-6 receptor monoclonal antibody (tocilizumab) was useful for treatment of CRS [12]. Apart from tocilizumab, anti-TNF $\alpha$ and anti-IL-1 receptor monoclonal antibodies are also commercially available. Combination of these anti-cytokine medications would be a promising approach for treating CRS. Accumulating a large number of thoroughly examined cases and the resulting better understanding of this disorder should provide safer cancer immunotherapy.

\section{Abbreviations}

ADAMST13: A disintegrin and metalloprotease with thrombospondin type 1 motifs; CRS: Cytokine release syndrome; HLH: Hemophagocytic
Iymphohistiocytosis; ICl: Immune checkpoint inhibitor; PF: Purpura fulminans; TTP: Thrombotic thrombocytopenic purpura

\section{Acknowledgements}

Not applicable.

Funding

None.

Availability of data and materials

Available upon request.

\section{Authors' contributions}

$\mathrm{OH}, \mathrm{FS}, \mathrm{TN}$ : Involved in care of the patient, wrote and edited this case report. TK, KK, YH: Analyzed clinical and pathological data, wrote and edited this case report. HT, TT conceived of the study and participated in the design, and the preparation of the manuscript. All authors read and approved the final manuscript.

Ethics approval and consent to participate

Not applicable, not a trial.

\section{Consent for publication}

Appropriate consent was obtained from the patient.

\section{Competing interests}

The authors declare that they have no competing interests.

\section{Publisher's Note}

Springer Nature remains neutral with regard to jurisdictional claims in published maps and institutional affiliations.

\section{Author details}

${ }^{1}$ Department of Respiratory Medicine, Sapporo Minami-Sanjo Hospital, Sapporo, Hokkaido 060-0063, Japan. ²Department of Pathology, Sapporo Medical University, School of Medicine, South 1, West 17, Chuo-ku, Sapporo, Hokkaido 060-8556, Japan. ${ }^{3}$ Sakaemachi Dermatology Clinic, Sapporo, Hokkaido 007-0841, Japan. ${ }^{4}$ Department of Respiratory Medicine, Teine Keijinkai Hospital, Sapporo, Hokkaido 006-8555, Japan. ${ }^{5}$ Department of Respiratory Medicine and Allergology, Sapporo Medical University, School of Medicine, Sapporo, Hokkaido 060-8543, Japan.

Received: 18 October 2018 Accepted: 28 March 2019

Published online: 03 April 2019

\section{References}

1. Suarez-Almazor ME, Kim ST, Abdel-Wahab N, Diab A. Review: immunerelated adverse events with use of checkpoint inhibitors for immunotherapy of Cancer. Arthritis Rheumatol. 2017;69:687-99.

2. Malissen N, Lacotte J, Du-Thanh A, Gaudy-Marqueste C, Guillot B, Grob JJ. Macrophage activation syndrome: a new complication of checkpoint inhibitors. Eur J Cancer. 2017:77:88-9.

3. Hantel A, Gabster B, Cheng JX, Golomb H, Gajewski TF. Severe hemophagocytic lymphohistiocytosis in a melanoma patient treated with ipilimumab + nivolumab. J Immunother Cancer. 2018;6:73.

4. Sadaat M, Jang S. Hemophagocytic lymphohistiocytosis with immunotherapy: brief review and case report. J Immunother Cancer. 2018;6:49.

5. Shah D, Shrestha R, Ramlal R, Hatton J, Saeed H. Pembrolizumab associated hemophagocytic lymphohistiocytosis. Ann Oncol. 2017;28:1403.

6. Takeshita M, Anai S, Mishima S, Inoue K. Coincidence of immunotherapyassociated hemophagocytic syndrome and rapid tumor regression. Ann Oncol. 2017:28:186-9.

7. King J, de la Cruz J, Lutzky J. Ipilimumab-induced thrombotic thrombocytopenic purpura (TTP). J Immunother Cancer. 2017;5:19.

8. Teraoka S, Fujimoto D, Morimoto T, Kawachi H, Ito M, Sato Y, et al. Early immune-related adverse events and association with outcome in advanced non-small cell lung cancer patients treated with Nivolumab: a prospective cohort study. J Thorac Oncol. 2017;12:1798-805.

9. Owen DH, Wei L, Bertino EM, Edd T, Villalona-Calero MA, He K, et al. Incidence, risk factors, and effect on survival of immune-related adverse 
events in patients with non-small-cell lung cancer. Clin Lung Cancer. 2018; 19:e893-900.

10. Sato K, Akamatsu H, Murakami E, Sasaki S, Kanai K, Hayata A, et al. Correlation between immune-related adverse events and efficacy in nonsmall cell lung cancer treated with nivolumab. Lung Cancer. 2018;115:71-4.

11. Pelosof LC, Gerber DE. Paraneoplastic syndromes: an approach to diagnosis and treatment. Mayo Clin Proc. 2010;85:838-54.

12. Shimabukuro-Vornhagen A, Godel P, Subklewe M, Stemmler HJ, Schlosser HA, Schlaak M, et al. Cytokine release syndrome. J Immunother Cancer. 2018;6:56.

13. Fardet L, Galicier L, Lambotte O, Marzac C, Aumont C, Chahwan D, et al. Development and validation of the HScore, a score for the diagnosis of reactive hemophagocytic syndrome. Arthritis Rheumatol. 2014;66:2613-20

14. Cifaldi L, Prencipe G, Caiello I, Bracaglia C, Locatelli F, De Benedetti F, et al. Inhibition of natural killer cell cytotoxicity by interleukin-6: implications for the pathogenesis of macrophage activation syndrome. Arthritis Rheumatol. 2015:67:3037-46.

15. Humblet-Baron S, Franckaert D, Dooley J, Bornschein S, Cauwe B, Schonefeldt $\mathrm{S}$, et al. IL-2 consumption by highly activated CD8 T cells induces regulatory T-cell dysfunction in patients with hemophagocytic lymphohistiocytosis. J Allergy Clin Immunol. 2016;138:200-09 e8.

16. Cao WJ, Niiya M, Zheng XW, Shang DZ, Zheng XL. Inflammatory cytokines inhibit ADAMTS13 synthesis in hepatic stellate cells and endothelial cells. J Thromb Haemost. 2008;6:1233-5.

17. Postow MA, Sidlow R, Hellmann MD. Immune-related adverse events associated with immune checkpoint blockade. N Engl J Med. 2018;378:158-68

18. Rotz SJ, Leino D, Szabo S, Mangino JL, Turpin BK, Pressey JG. Severe cytokine release syndrome in a patient receiving PD-1-directed therapy. Pediatr Blood Cancer. 2017;64:e26642.

19. Oda H, Ishihara M, Miyahara Y, Nakamura J, Kozuka Y, Iwasa M, et al. First case of cytokine release syndrome after nivolumab for gastric cancer. Case Rep Oncol. 2019;12:147-56.

20. Zhao L, Yang Y, Li W, Li T, Gao Q. Nivolumab-induced cytokine-release syndrome in relapsed/refractory Hodgkin's lymphoma: a case report and literature review. Immunotherapy. 2018;10:913-7.

Ready to submit your research? Choose BMC and benefit from:

- fast, convenient online submission

- thorough peer review by experienced researchers in your field

- rapid publication on acceptance

- support for research data, including large and complex data types

- gold Open Access which fosters wider collaboration and increased citations

- maximum visibility for your research: over $100 \mathrm{M}$ website views per year

At $\mathrm{BMC}$, research is always in progress.

Learn more biomedcentral.com/submissions 